\title{
Leri pleonosteosis
}

INSERM

\section{Source}

INSERM. (1999). Orphanet: an online rare disease and orphan drug data base. Leri pleonosteosis. ORPHA:2900

Leri pleonosteosis is characterized by broadening and deformity of the thumbs and great toes in a valgus position (a 'spade-shaped' appearance), flexion contracture of the interphalangeal joints, generalized limitation of joint mobility, short stature, and often mongoloid facies. Additional malformations include genu recurvatum, enlargement of the posterior neural arches of the cervical vertebrae, and thickening of the palmar and forearm fasciae. A few multigenerational families have been reported so far. The disease is inherited in an autosomal dominant manner. 